\title{
Forty years later - The value of praise, ignoring, and rules for preschoolers at risk for behavior disorders *
}

\author{
Translated by Erten GÖKÇE ${ }^{* *}$
}

\begin{abstract}
The pivotal role of teachers in establishing positive, supportive, inclusive learning environments based on the implementation of empirically-supported teaching strategies (IDEA, 1997, 2004: NCLB, 2002) is uncontestable. Nonetheless, it is not uncommon to find classrooms characterized by teacher reprimands for inappropriate behavior, coercive interchanges between teachers and children, and limited use of positive teacher feedback. This suggests a need for teachers to implement scientifically supported strategies for promoting positive social and academic growth of young children at risk for behavioral disorders. In the context of a multi-tiered approach to positive behavior supports, we decided to revisit three classroom-level interventions strategies for which there is longitudinal evidence regarding their efficacy-namely, praise, planned ignoring, and classroom rules. Each is discussed, along with guidelines for use by classroom teachers with the goal to improve teacher-child relationships, build positive learning communities, and manage difficult behaviors.
\end{abstract}

\footnotetext{
* Translated from: Hester, P.P., Hendrickson, J. M., Gable, R. A.,(2009). "Forty Years Later-The Value of Praise, Ignoring, and Rules for Preschoolers at Risk for Behavior Disorders", Education and Treatment of Children, Vol:32, No: 4, p: 513-535.

** Assoc. Prof. Dr., Ankara University, Faculty of Educational Sciences, Ankara,Turkey.

E-mail:gokce@education.ankara.edu.tr
} 


\title{
Kırk Yıl Sonra - Davranış Bozukluğu Gösterme Riski Olan Okulöncesi Çağı Çocuklar için Kuralların, Övgünün ve Planlı Aldırmazlığın Önemi*
}

\author{
Çeviri Makale - Erten GÖKÇE ${ }^{* *}$
}

ÖZ. Ampirik olarak desteklenmiş öğretim stratejilerinin (IDEA, 1997, 2004: NCLB, 2002) uygulanmasına dayalı olarak öğretmenlerin olumlu, destekleyici, kapsamlı öğrenme ortamları oluşturmadaki önemli rolleri tartışılmaz. Bununla birlikte, yanlış davranışları azarlayan öğretmenlerle, öğretmenler ve öğrenciler arasındaki karşılıklı zorlayıcı değişimlerle ve olumlu öğretmen dönütünün sınırlı kullanımıyla karakterize edilen sinıflar bulmak olağan bir durumdur. Bu durum, davranış bozukluğu riski altındaki küçük çocukların olumlu sosyal ve akademik gelişimlerini artırma konusunda öğretmenlerin bilimsel olarak desteklenmiş stratejileri uygulama gereksinimlerine işaret eder. Olumlu davranış desteklerine olan çok katmanlı bir yaklaşım ortamında, etkinliklerine ilişkin boylamsal bir kanıtın bulunduğu övgü, planlı aldırmazlık ve sınıf içi kurallar olmak üzere üç adet sınıf düzeyi müdahale stratejilerini tekrar değerlendirmeye karar vermiş durumdayız. Her biri, öğretmen-öğrenci ilişkilerini geliştirmek, olumlu öğrenme grupları oluşturmak ve zor davranışları yönetmek amacı yanında, sınıf öğretmenleri tarafından kullanılacak ana esaslarla birlikte ele alınmaktadır.

\footnotetext{
* Hester, P.P., Hendrickson, J. M., Gable, R. A.,(2009). "Forty Years Later-The Value of Praise, Ignoring, and Rules for Preschoolers at Risk for Behavior Disorders", Education and Treatment of Children, , Sayı:32, No 4, Sf: 513-535 kaynaklı makaleden çevrilmiştir.

** Doç. Dr., Ankara Üniversitesi Eğitim Bilimleri Fakültesi Ankara,Türkiye.

E-posta:gokce@education.ankara.edu.tr
} 


\section{GíRiş}

Öğretmenlik mesleğine duyulan memnuniyetsizlik nedeniyle mesleğini bırakan devlet okullarındaki öğretmenler için ana neden sınıftaki davranış sorunları olmuştur (Ulusal Eğitim İstatistikleri Merkezi, 2002). Ne yazık ki, okullarda yaygın olarak görülen disiplin sorunlarının çoğu ilk çocukluk yıllarındaki davranış yapılarından kaynaklanmıştır (Webster-Stratton, 2000). Tahminler farklı olsa da, okul çağındaki popülasyonun yaklaşık \% 3-6'sı duygusal/davranışsal sorunlar yüzünden özel eğitim hizmetlerine gerek duymaktadırlar (Kauffman\&Landrum, 2009).

Ayrıca araştırma, \% 7-25 oranında küçük yaştaki çocuğun davranış bozukluklarını dıșa vurduklarını göstermiștir (Loeber, Burke, Lahey, Winters\&Zera, 2000). Webster-Stratton'a göre (1997) davranış sorunları bulunan okul öncesi yaştaki çocuklar, daha sonra özel eğitim hizmetlerine ihtiyaç duymaktadır. Genelde yetersiz sosyal-duygusal uyum, ilerideki akademik sorunlarla ilintilidir (Loeber, 1990; Markowitz ve diğerleri, 2006). Zorluk arz eden davranışları olan çocuklar, diğer çocuklara nazaran daha az destek, yetersiz gıda ve olumsuz dönüt almaktadırlar (Raver\&Knitzer, 2002; Shores, Gunter\&Jack, 1993). Son olarak, hem öğrenciler hem de öğretmenler, zorluk arz eden davranışlar sergileyen çocukları dışlama eğilimindedirler (Kendziora, 2004).

Sınıfa uygun davranış repertuarıyla okul eğitimine başlayan çocuklar, büyük olasılıkla başarılı öğrenciler olacaklardır (Conroy, Hendrickson, \&Hester, 2004; Sugai\&Horner, 2006). Bununla birlikte, davranış sorunları olan veya risk taşıyan genç çocuklar için başarılı ilk müdahalelere dair ampirik kanttlara rağmen (örn, McEvoy\&Welker, 2000; Strain\&Timm, 2001, Webster-Stratton, 2000), yanlış davranışları azarlayan öğretmenlerle (Van Acker, 2004), öğretmenler ve öğrenciler arasındaki karşılıklı zorlayıcı değişimlerle (Kern, White \&Gresham, 2007; Shores ve diğerleri, 1993) ve olumlu öğretmen dönütünün sınırlı kullanımıyla (Sugai\&Horner, 2006) karakterize edilen siniflar bulmak olağan bir durumdur. $\mathrm{Bu}$ durum, öğretmenlerin öğrencinin olumlu sınıf davranışlarını geliştirmeleri için gereken becerilere sahip olmaları gerektiğini vurgulamaktadır (Kenziora, 2004).

Araştırmacılar (örn., Dodge; 1993; Kaiser\&Hester, 1997) uzun süredir büyük ölçüde öğretmen-öğrenci etkileşimlerinin doğasıyla saptanan kaliteli ilk çocukluk eğitiminin önemini vurgulamışlardır ( DeKruif, McWilliam, Ridley, \&Wakely, 2000). Yani, kaliteli öğretim sadece müfredat içeriğinden değil ama aynı zamanda öğretim sürecinden, bir başka deyişle öğretmenlerin müfredatı nasıl uyguladıkları ve öğrencilerle nasıl etkileşime girdiklerinden kaynaklanır (DeKruif ve diğerleri, 2000; Pianta, 2006). Bu kavramlaştırma, zorluk arz eden davranışları olan çocuklara öğretmenlik yapan öğretmenlerin çok önemli olan rollerinin ve ampirik olarak desteklenen öğretim 
stratejilerinden kaynaklanan olumlu, destekleyici, kapsamlı öğrenme ortamlarını oluşturma amacının üzerinde durur (IDEA, 1997, 2004: NCLB, 2002). Olumlu davranış desteklerine olan çok katmanlı yaklaşıma yapılan mevcut vurguyla (Sugai\&Horner, 2006), etkinliklerine ilişkin boylamsal bir kanıtın bulunduğu övgü, planlı aldırmazlık ve sinıf içi kurallar olmak üzere üç adet sınıf düzeyi müdahale stratejilerinin tekrar değerlendirilmesi kararlaştırılmıştır.

Küçük yaştaki çocukların olumlu, uyumsal davranışlarını desteklemek amacıyla en yaygın şekilde araştııılmış bu üç strateji övgü, planlı aldırmazlık ve sınıf içi kurallardır. Bu stratejiler önce araştırılmış ve 40 yılı aşkın bir süredir önerilmiştir (örn, Becker, Madsen, Arnold \& Thomas; 1967; Madsen\&Becker\& Thomas; 1968; Zimmerman\&Zimmerman, 1962). Ampirik desteğe karşın, öğretmenlerin hepsi bu stratejilerden sürekli olarak yararlanmazlar. Olumlu ögrrenme toplulukları oluşturmak, çocukların akademik ve sosyal öğrenmelerini geliştirmek ve küçük yaştaki çocukların zorluk arz eden davranışlarını yönetmek 40 yıl öncesine göre muhtemelen bugün daha kolaydır. Öğretmen övgü, planlı aldırmazlık ve sınıf içi kurallar gibi temel stratejileri ustalıkla nasıl uygulayacağını bilmez ise, günümüz sınıflarını karakterize eden büyük çeşitlilik yelpazesi yüzünden bu amaçlar anlaşılması zor hale gelir. Aşağıdaki tartışmada övgünün, planlı aldırmazlığın ve sınıf kurallarının sınıf ve çocuk üzerinde çok büyük olasılıkla olumlu etkisinin olacağı durumları incelemekteyiz ve vurgulamaktayız ve sonuçları olumsuz etkileyecek faktörleri ele almaktayız ve uygulamaya dair örnekler vermekteyiz.

\section{Övgü}

Basitçe açıklamak gerekirse, övgü bir hedef davranışı izleyen (kimi zaman geçici olarak çakışır) sözel bir ifadedir. Genel amaç olumlu dönüt sağlamak, hedef davranışın gerçekleşmesini teşvik etmek ve desteklemektir (Örn, paylaşım, düzgün performans ve çalışmalara katılım). Dolayısıyla, övgü uygun zamanda ve uygun şekilde yapılmış ise görev, durum ve hedef davranış olasılıkla güçlendirilecek ve ileride tekrar gerçekleşecektir. Zimmerman ve Zimmerman (1962), Becker, Madsen, Arnold ve Thomas (1967) ve Madsen, Becker ve Thomas (1967) ile başlatılan ampirik çalışmalar sayesinde öğretmenin övgüyü kullanması durumu çocukların doğru tepkilerindeki, çalışmalara katılma düzeyindeki ve uygun davranış sıklığındaki artışlarla ilişkilendirilmiştir. Övgünün etkinliği, bir davranışın hemen ardından gelen bir sonucun ( $b u$ durumda övgü) o davranışın güçlendirilmesiyle sonuçlandığını ve kişinin (örn, çocuk) ileride bu davranışı büyük olasılıkla tekrar sergileyeceğini belirten uygulamalı davranış analizi prensibi olan olumlu pekiştirmeye dayanmaktadır (Alberto\&Troutman, 
2009; Kerr\& Nelson, 2010). Tam tersine, hedef davranışta azalma olursa, davranışın etkinliğini artırmak için övgüyle ilintili değişkenlerin tekrar incelenmesi ve/veya değiştirilmesi gerekir. Belirtildiği gibi, övgü y1llar boyunca olumlu öğretmen-çocuk ilişkisini geliştirmede ve destekleyici öğrenme ortamlarını oluşturmada bir kilit strateji olarak belirlenmiştir (Gable, Hester, Rock\&Hughes, 2009; Stormont, Smith \&Lewis, 2007; Walker, Colvin\&Ramsey, 1999). Eski ve geçerli bu stratejiden yararlanmak için etkili birkaç rehber bulunmaktadır. Sonraki bölümde övgünün etkinliğini etkileyen çok önemli faktörleri ele almaktayız. Bunlar (a) Şarta bağlılık, (b) İvedilik, (c) Tutarlılık, (d) Davranış üzerindeki etki, (e) Yakınlık, (f) Özgüllük, (g) Tepki verme firsatları ve (h) Sonucun özellikleridir. Ayrıca, övgü yapılırken, ortaya çıkabilecek ikincil etkileri de ele almaktayı.

\section{Şarta Bağlılık}

Hedef davranışla bir övgü ifadesi arasındaki ilişki şarta bağlılık olarak bilinir. Hedef davranış gerçekleştiğinde, tahmin edileceği gibi arkasından öğretmenin övgüsü gelmek zorundadır. Şarta bağl1lık övgüsünün kullanımının güçlü ampirik desteği bulunmaktadır (Stormont ve diğerleri, 2007; Strain\& Joseph, 2004). Örnek vermek gerekirse, öğretmen uygun şekilde davranış sergileyen çocuğu (örn, soruyu doğru yanıtlamak, bir görevle meşgul olmak veya sınıf arkadaşıyla olumlu şekilde etkileşimde bulunmak) överse, hedef davranışla ilgili koşullu durumu övmüş olur. Davranış ve övgü ifadesi (pekiştireç) arasındaki geçici ilişki, şarta bağlıdır.

Bir hedef davranışın oluşumunda koşullu şekilde yapılan övgünün de ikincil etkileri olabilir. Örneğin, Jennifer paylaşmayı sevmediğinden onun işbirlikçi davranışını geliştirmek (özellikle paylaşımcılığını) hem annesi hem de öğretmeni tarafından belirlenmiş bir öncelikli hedeftir. Bir öğleden sonra Jennifer oyun hamuruyla masada oynamaktadır ve diğer çocukların elindeki malzemeleri kullanmasina nadiren izin verse de, Jennifer oval kurabiye bıçağını Scott'a uzatır. Jennifer'in öğretmeni destekleyici övgüyü kullanmak için bu durumdan yararlanır. "Jennifer! Kurabiye biçağını Scott ile paylaşman çok güzel bir şey," der. Jennifer gülümseyerek ve gözleri parıldayarak bir başka kurabiye bıçağını Scott'a uzatır. Bunun karşılığında, öğretmen uyanık oluşuyla, paylaşımcı davranışı gözlemesiyle, yaptığı işi kısa süreli bırakarak Jennifer'i övmesiyle pekiştirilmiş olur. Öğretmen daha sonra Jennifer'in annesine e-postayla ileteceği şeyleri aklının bir köşesine yazarak ona "Jennifer, bugün bir şeyler paylaştığından ötürü annenin senle gurur duyacağını biliyorum, bunu ona anlatmak için sabırsılanıyorum," der. Koşullu olarak uygulanan övgüye dair bu basit hareket, Scott'la ikinci bir kurabiye bıçağını paylaştığından ötürü Jennifer'i pekiştirmekle kalmaz ama 
aynı zamanda diğer bir dizi olumlu davranış destek stratejilerinin pekiştirilmesiyle ilgili ikincil yararlar sağlar (Örn., aile ile olumlu iletişim).

\section{İvedilik}

Övgünün etkili olabilmesi için özellikle çocuğun henüz tam öğrenmediği bir davranıştan ötürü yapılmış ise, davranış gerçekleştikten hemen sonra yapılmalıdır. Bir görevin doğruluğunu vurgulayan çabuk yapılan bir övgü (Hattie\&Timperley, 2007) hedef davranışa odaklanmanın sürdürülmesine yardımc1 olur. Övgü gecikirse, umulmadık ikincil etki potansiyeli ortaya çıkar. Örneğin, Bay Johnson, Devon ne zaman parmak kaldırsa ona "Aferin" demeye özen gösterir ancak Devon'un artık parmak kaldırmadığını fark etmeye başlamıştır. Bay Johnson bu durumu paraprofesyonellerle görüştüğünde, bir paraprofesyonelin kendisine "parmak kaldırmayı" değil de, "boyama çalışmasını" övmüş olduğunu gerçektende düşündüğünü söylemesi üzerine şaşkınlık içersinde kalır. Bay Johnson, Devon'un zorluk çıkarıcı bir yapısının olmadığından memnun olsa da, övgüsünün gecikmiş olduğunu fark etmiştir. "Parmak kaldırma" hedef davranışını değil de, "boya çalışması" davranışını pekiştirmiştir. Öğretmen, Devon'un parmağını kaldırmasından veya parmağını kaldırması istendikten hemen sonra Devon'u övmesi gerektiğini anlamıştır.

\section{Tutarlılık}

Çocuklar davranış destekleri tutarlı şekilde uygulandığında daha başarılı olurlar (Sugai\&Horner, 2006). Sistematik olarak yapılan övgü, özellikle yeni bir beceri veya davranış öğreten öğretmenin kontrolü altındaki önemli olumlu davranış destek stratejilerinden birisidir (Alberto\&Troutman, 2009). Övgü öngörülemiyor ise, yani kimi zaman bir davranış övülüyor kimi zaman övülmüyor ise, karışıklık ortaya çıkabilir.

Öğretmenlerin övgüyü kullanırken abartıya kaçmaları yaygın bir durumdur. Öğretmenler övgüyü uygun şekilde ve sık olarak kullandıklarına inanabilirler ancak onların bu çabalarına karşın, aynı öğrenciler yanlış davranış sergilemeyi sürdürürler. $\mathrm{Bu}$ türden öğretmen yaklaşımları, öğretmenlerin bir dizi öğretim stratejisinin kullanımını algılama durumuyla, onların bu stratejileri sınıfta fiili olarak kullanımı arasındaki farklılığ belgeleyen ampirik literatürde destek bulmaktadır (Anderson\&Hendrickson, 2007; Shores ve diğerleri, 1993 bakınız). Örneğin, davranış bozuklukları olan öğrenciler için sınıflarda kullanılan övgü oranları, bu araştırmalara göre her öğrenci için saat başına 1,2 ile 4,5 aralığındadır. Oysa azarlamaların övgü ifadelerine oran1 3'e 1'dir (Sutherland\&Wehby, 2001). Bu çalışmada öğretmenlerin övgüye nazaran 3 kat daha fazla azarlama ifadesi 
kullandıklarına inanmaları olası değildir ancak algı ve sınıf realitesi s1k olarak çakışmaz. Gerçekte, öğretmenlerin düşük performans sergileyen öğrencilerle olan etkileşimlerinde azarlama ifadelerinin kullanımı bir hayli öngörülebilir bir durumdur (Van Acker, Grant, \& Henry, 1996).

Uygulamalı davranış analiz prensipleri belirgindir - Öğretmen yeni bir davranış1 öğretirken uygun davranış gerçekleştiğinde yapılan tutarlı övgü (pekiştirme), yapılan en iyi övgüdür (Alberto\&Troutman, 2009). Dolayısıyla, öğretmenlerin sınıflarda yapmayı arzuladıkları şeyle fiilen yaptıkları şey arasında bir bağlantısızlığın olabileceği gerçeğinin farkında olmaları çok büyük önem taşır. Müdahale uygunluğu için özdenetim prosedürleri (örn, ara sıra videokasetlerle, akran danışmanlığıyla ), öğretmenlerin övgü gibi destekleyici öğretim davranışlarını tutarlı şekilde kullanma olasılığını artırabilir (Gable ve diğerleri, 2009). Bir davranış oluşturulur oluşturulmaz (veya öğrenilir öğrenilmez), övgünün mantıklıca ara ara kullanımıyla o davranış sürdürülebilir (Alberto\&Troutman, 2009; Kerr\&Nelson, 2010) ve daha sık övgü ifadeleri için yeni davranışlar belirlenebilir.

Öğrenci dolu bir sınıfta gün boyunca hedef davranışın gerçekleştiği her an öğretmenin tek bir çocuğu övmesini beklemek mantıksız olsa da, tutarlı övgü, yeni bir davranışın öğretilmesinde kilit bir unsur olmayı sürdürür. Çözüm basittir. Çocuğun geliştirmesi gereken çok önemli bir beceriyi veya davranışı belirlemekle başlar ve etkinlik veya zaman süresi, başarı için çok büyük firsat sunacaktır. Çocuğun hedef davranışı arttıkça ve bu dar zaman süresi boyunca sürdükçe, öğretmen bu zaman süresi boyunca ara ara övgülerle hedef davranışı sürdürebilir ve tutarlı övgülerde bulunmak için bir diğer zaman süresini veya etkinliği seçebilir.

\section{Davranış Üzerindeki Etki}

Övgünün olumlu öğrenci davranışını artırmadaki etkinliğine dair ampirik kanıta rağmen, övgü, her zaman her öğrenci veya belli bir öğrenci için kesinlikle olumlu bir pekiştireç olmaz (Brophy, 1981). Övgünün yararlılığını saptamak için öğretmen onun çocuk üzerindeki etkisini gözlemelidir (Brophy, 1981). Gözlemci durumundaki öğretmen övgünün bir öğrenci için olumlu, bir diğer öğrenci için olumsuz olacağını dikkate alacaktır (Ollendick\&Shapiro, 1984). Çocuk övgülerle karşılandığı görevini sürdürürse, gülümsemeyle memnuniyetini ifade ederse, övgünün etkili şekilde uygulanmış olması olasıdır. Öte yandan, öğrenci hedef davranışla ilgilenmeyi bırakıp uygunsuz davranışlar sergiler, kaşlarını çatıp, ters cevaplar verirse, övgünün tercih edilmeyen bir müdahale olması olasıdır.

Övgünün çocuk üzerindeki etkisi de çocuğun gelişimsel düzeyiyle (Spiker, Hebbeler, \&Mallik, 2005) ve ilgi becerısı ya da davranışna ilişkin ögrenme aşamasıyla (Pianta, La Paro, Payne, Cox, \&Bradley, 2002) 
ilintilidir. Çocuk belli bir beceride çok yetenekli ise, övgü çocuğun performansını gerçekten kötüleştirebilir (Kast\&Connor, 1988). Üstelik öğretmenin çocuğu akranları arasında övmesi, çocukların öğretmenin övgülerinin huzursuz edici olduğunu düşünmesi (Brophy, 1998; Long\&Morse, 1996) veya öğretmenin tanımak amaciyla diğer öğrenciler arasından kendisini seçmesini istemedikleri (Feldman, 2003) takdirde, övgü ters tepebilir. Ayrıca, övgünün aykırı bir etkisi olabilir çünkü bazı çocukların öğretmenlerini memnun etme gibi bir arzusu yoktur. Bu çocuklarla ilgili öğretmen övgüsünün pekiştirici değerini artırmak için, çocuğun çok hoşlandığ 1 faaliyetleri yürütürken övgüde bulunulması önerilmektedir. Her halükarda, öğretmenlerin, övgü ifadelerinin çocukların performansı üzerindeki etkisini izlemeleri esastır. Vurguladığımız gibi, etkili övgü ifadeleri, çocuğun öğrenme grubuna olumlu şekilde katılımını sürdüren veya artıran ifadelerdir. Son olarak, övgünün kullanılmasının, akademik beceri eksikliklerinin doğrudan öğretilmesinin önemini ve görev performansının belli yönlerine yönelik olumlu ve/veya düzeltici dönüt kullanımını yadsımadığını göz önünde bulundurmak önemlidir.

\section{Yakınlık}

Genel anlamda, çok yakın olma durumu özellikle bir çocuk övüldüğü zaman avantaj sağlar (Feldman, 2003; Shores ve diğerleri, 1993). Öncelikle, çok yakın olma durumu, öğretmenin öğrencinin dikkatini kendi üzerinde topladığından ve çocuğun verebileceği ivedi, ince tepkilerini gözleyebildiğinden (örn, gülümseme, fiziksel gerginlik) emin olmasını sağlar. İkincisi, öğretmen rekabetçi ortamsal uyarıları (örn, gürültü düzeyi, görsel dikkat dağıtıcı şeyler) bir dereceye kadar "bloke" edebilir ve öğrencinin övgü ifadesinin olumlu amacını anlamasını sağlar. Üçüncüsü, öğretmen süregelen bir faaliyete katılarak, çocukların bir arada bulundukları yere giderek veya özel bir söyleşi için çocuktan yanına gelmesini isteyerek yakınlık kurabilir.

Öte yandan, çocuğa çok yakın olma durumu, her zaman olanaklı olmayabilir ve genel anlamda firsatı kaçırmaktansa övgüde bulunmak daha iyidir. Böyle durumlarda gruba yapılacak övgü bir alternatif oluşturur ve öğretmen, gruba hitaben yapılacak övgü bağlamında iki veya daha fazla çocuğu ismen belirleyebilir (örn, “ bu ekip bireyleri sırayla iyi iş çıkarıyor. Jeremy, Dakota ve Allison! Diğerleriyle paslaştığınız için sizlere teşekkür ederim!"). Öğretmen küçük veya büyük bir öğrenci grubunu övmek istediği takdirde (örn, "Timsah ekibi! Oyuncakları toplayarak harika bir iş yapıyorsunuz!"), öğretmen diğerlerine nazaran bazı çocuklarla ister istemez daha fazla yakınlık kuracaktır. Çocuklar için öğretmenin yaptığı övgü henüz pekiştirici değil ise, gruba hitaben yapılan övgü, öğretmenin çocuğun 
ödüllendirilmesine yönelik olarak övgüde bulunabileceği ilk adım stratejisi olabilir.

Hatta övgü, bir birincil pekiştireçle tekrar tekrar eşleştirilerek daha çarpıcı olabilir ve pekiştirici özellikleri benimseyebilir (örn, övgünün, çok sevilen bir oyuncağa veya faaliyete erişebilir olma durumuyla eşleştirilmesi). Dahası grup olumsallıklarının kullanımı, artan akran etkileşimini ve diğerleriyle dayanışma içersinde olmayı güçlendirebilir (McCarty, Griffin, Apolloni\&Shores, 1977).

\section{Belirlilik}

İlk araştırmacılar (Becker ve diğerleri, 1967; Zimmerman\&Zimmerman, 1962) olumlu davranışları ve doğru tepkiyi izleyen övgü ifadelerinin kullanımını savunmuşlardır ve en iyi uygulamaları yürüten ilk çocukluk dönemiyle ilgili programlar, öğretmenin "Aferin oğlum”, "Aferin kızım" ifadelerinin yankılariyla dolmuştur. Bu temel yaklaşım, çocuğun davranışının sıklığını artırmada etkili olsa da, genel yararı olumlu davranış destek stratejisi olarak sınırlıdır. Övgü ifadesinin aşırı ve gereğinden fazla kullanılması, övgüyü pekiştirici olmaktan çıkarabilmesi muhtemeldir (Alberto\&Troutman, 2009). Aslında, ifadeler dinleyiciye itici geldiğinden, bu tür ifadelerin bazı çocuklarda uygunsuz davranışları tetiklemeye başlaması umulmadık bir sonuç olarak ortaya çıkabilir. İkincil olaylar zinciri, "övgüyü denese de işe yaramadığını", "sınıfında idare edilmesi güç öğrencilerin olmadığını," "olumsuz davranışın tırmanmasını önlemek için belli öğrencilerle iletişime geçmemenin daha iyi olacağını" ifade eden öğretmenin algılama biçimini kapsayabilir.

Öğretmenin geliştirmeye çalıştığı davranışı özellikle açıklayan övgü, çocuğa olasılıkla itici veya gereksiz gelmeyecek ve "aferin" gibi ifadelerden olasılıkla daha etkili olacaktır (Feldman, 2003). Görevle ilgili özel bilgiler içeren ifadeler, genel övgü ifadelerinden daha etkilidir (Hattie\&Timperley, 2007; Stormont ve diğerleri, 2007). Özel övgü ifadeleri, "Megan! Kalemtıraşın yanına kadar gittiğin için teşekkürler!" "Lu! Arkadaşın Kena’yla sessizce oynaman ne güzel!” ve “ $\mathrm{Ne}$ kadar güzel boyama yapıyorsun, Ricco! Kullandığın renklerin hepsine bayıldım” gibi ifadeleri kapsar. Bu tür ifadeler, özellikle yeni bir beceri öğrenen veya bir beceriyi veya belli bir davranışı yerine getirme konusunda kaygılanan bir çocuk için yararlıdır. Son olarak, övgüyü doğru kullanmanın, diğer çocukların öğretmenlerini ve kafalarında bulanıklığa yol açabilecek sınıf beklentilerini anlamalarını sağlama konusunda potansiyel ikincil etkisi bulunur (Gable ve diğerleri, 2009). 


\section{Tepki Verme Firsatları}

Sutherland, Wehby ve Yoder (2002), duygusal ve davranışsal bozuklukları olan öğrencilerle ilgili bir örneklemde öğretmenin övgü dolu sözler söylemesiyle, akademik taleplere tepki gösterme firsatları arasında anlamlı bir ilişkinin olduğunu ortaya koymuşlardır. Yüksek övgü oranlarına sahip olan öğretmenler, öğrencilere tepkilerini gösterecek pek çok firsat tanımaktadırlar. Tam aksine, düşük övgü oranları olan öğretmenler ise öğrencilere daha az tepki gösterme firsatları vermişler ve dolayısıyla, genel öğrenme oranını ve olumlu öğretmen-çocuk etkileşimi genel oranını düşürmüşlerdir. Öğretmenlerin çocuklarla ilgili övgü oranlarını geliştirmelerinin etkili bir yolu, öğrencilere sık olarak tepki gösterme firsatları verecek (doğru şekilde tepki göstermeleri için) olan eğitici görev serilerini planlamaktır. Tepki firsatları sayısının proaktif olarak artırılması, başarılı öğrenci performansı için, öğretmenin özyeterlilik duygusunu artırma olasılığının yanı sıra, öğretmenin övmesi için daha fazla örnek (Sutherland ve diğerleri, 2002) ve daha fazla firsat oluşturmaktadır. Üstelik daha yüksek orandaki olumlu öğretmen-çocuk etkileşimi, öğretmenin öğrencilerle ilgili öğrenme potansiyeli fikrini ve onun sınıf içi öğrenme ortamındaki yerini olasılıkla geliştirecektir.

\section{Sonucun Özellikleri}

Davranışsal teoriye göre, bir pekiştirecin (örn, övgü) etkili olması için davranış1 sürdürülecek veya değiştirilecek öğrenci, pekiştireçle ilişkili olarak göreceli bir yoksunluk durumu içersinde olmalıdır (Alberto\&Troutman, 2009). Bu nedenle, aynı ifade tekrar tekrar kullanıldığı takdirde, övgünün etkinliği azalmaktadır (Brophy, 1981; Kast\&Connor, 1988). Öğrenci, öğretmenin övgülerinin içten olmadığını ve kendisini belli bir tarzda davranışa yöneltme amacı taşıdığını anladığında, övgü ifadesi, çocuğun içsel motivasyonunu ( Kast \&Connor) ve görev veya faaliyetten haz duymasını gerçekten de azaltabilir. Çocuk bir beceriyi edinir edinmez, öğretmen çocuk sırasında dik oturduğunda, uygun şekilde kuyrukta beklediğinde ve dikkatlice dinlediğinde övgü ifadelerini kullanmaya devam ederse övgü çok ilgisiz hale gelebilir (Brophy, 1988).

Sezgisel ve ampirik olarak biliyoruz ki, şevkle yapılan övgü, pekiştirici değerini büyük olasılıkla koruyacaktır (Filcheck, McNeil, \&Herschel, 2001). Buna ilaveten, övgü, çocuğun davranış ve performans düzeyine uygun olmalıdır (Hattie, 1993; Sugai\&Horner, 2006). Övgü ifadeleri yeni ve değişik ise daha etkili olur. Bunlar çocuğun yaşına uygun hedef davranışa özgü olmalı ve çocuğun beğenilerini, antipatilerini ve eski performansını dikkate almalıdır. Herhangi bir çocuk için yararlı olan övgü, bir başka çocuk 
için yararlı olmayacaktır. Davranış bozuklukları riski altındaki genç çocuklar için övgü ifadelerinin çoğu ortamlarda birbirlerine benzemesi muhtemel olsa da, öğretmenlerin her çocuğu tanıması, olumlu bir ilişki kurması ve o çocuğa uygun en iyi övgü ifadelerini belirlemesi özellikle önemlidir.

Özetlemek gerekirse, davranış bozuklukları riski taşıyan genç çocukların öğretmenlerinin ve çocuk bakımı görevlilerinin ellerinde övgü gibi çok güçlü bir araçları bulunur. Öğretmenin övgüde bulunması, çocuğun davranışını geliştiren, öğretmen-çocuk ilişkilerini olumlu şekilde etkileyen ve öğretmenlerin özyeterlilik duygularını artıran iyi belgelenmiş bir stratejidir. Yine de, övgünün etkili olması ve çocuğun davranışı üzerinde ivedi etki sağlaması için özenle yapılmalıdır. Övgünün pekiştirici özelliğini sürdürme stratejileri övgünün koşullu şekilde, ivedilikle ve tutarlıca uygulanmasını kapsar. Özel tarzda övgüde bulunulması ve övgüde bulunurken öğrenciye çok yakın olunması önerilmektedir. Son olarak, öğretmenler çocukların tepki göstermesi açısından pek çok firsat sağlayacak ders planlaması yaparak, övgüde bulunmak için kendilerine daha fazla firsat sağlarlar ve çocuklarda artan sayıda önemli becerileri uygulama ve edinme şans1 yakalarlar.

\section{Öğretmenin Planlı Aldırmazlığı (Görmezden Gelme) Kullanması}

Spira ve Fischel'e (2005) göre, dört yaş civarında çocuğun dikkatini yönlendirme ile formal ve yapılandırılmış ortamlarda işlev kabiliyetinde önemli bir artış meydana gelmektedir. Ayrıca, çocuklar daha öz denetimci davranışlar geliştirmektedir. Doğru kullanıldığında, planlı aldırmazlık çocuğa uygun ve uygun olmayan davranışları ayırt etme konusunda yardımcı olabilmektedir. Kısmi rahatsılılı verici veya uygun olmayan davranışları azaltma aracı olarak planlı aldırmazlığın kullanılması için, öğretmenin öncelikle öğretmen/yetişkin ilgisinin çocuk için pekiştirici olduğu varsayımını kabul etmesi gerekmektedir. Planlı aldırmazlık, temelde davranışın pekiştirecini birden bire geri çekerek yada sonlandırarak bir davranışı zayıflatmak, azaltmak veya ortadan kaldırmak için tasarlanmış bir söndürme prosedürüdür (Sheuermann\&Hall, 2008). Örneğin, öğretmen bir çocuğun "sızlanma" davranışıyla ilgilenmediğinde, bu çocuğa sızlanmanın öğretmenin dikkatini çekmeyeceği uyarısını vermektedir (Alberto\&Troutman, 2009; Kerr\& Nelson, 2010). Eğer öğretmen, sızlanan çocuğa arkasını dönerken "Kelimeler kullanmayı, unutma" derse, öğretmen çocuk için uygun bir alternatif modeli göstermiş olur. Bundan sonra, sistematik planlı aldırmazlık ile eşleştirilmiş uygun ses tonu ve kelime kullanımı için ilginin birleştirilmesi, hedef davranışın zayıflaması veya sona ermesi ile sonuçlanmalıdır (Ryan, Sanders, Katsiyannis, \&Yell, 2007). Ancak, söndürme eyleminin davranışı sürdüren pekiştirecin ortadan 
kaldırılması anlamına geldiğine dikkat edilmelidir. Hedef bir davranışa aldırmamak sadece pekiştirecin ilgi noktası olduğu durumlarda davranışı azaltacaktır (Alberto\&Troutman). Bunu açıklamak gerekirse, eğer bir çocuk bir oyuncağı sınıfın dışına çıkarır ve öğretmen buna aldırmazsa, aldırmama eyleminin oyuncağı alma davranışını zayıflatması olası değildir. Bu durumda davranışın işlevi öğretmenin dikkatini çekmek değil de oyuncağı almaktır.

Övgünün etkin kullanımı hakkındaki değerlendirmemizde olduğu gibi, planlı aldırmazlığın etkin uygulamasındaki kritik etkenleri inceleyeceğiz. $\mathrm{Bu}$ etkenler övgüyü başarılı bir şekilde kullanmak iççin gereken ilkelere paraleldir. Bu ilkelere şunlar dahildir (a) planlı aldırmazlığın pekiştirme stratejileri ile eşleştirilmesi, (b) şarta bağll1ık, (c) ivedilik, (d) tutarlılık, (e) belirlilik, (f) planlı aldırmazlığın özellikleri ve (g) davranışın etkisi.

\section{Planlı Aldırmazlığın Pekiştirme Stratejileri ile Eşleştirilmesi}

Uygun olmayan bir davranışı azaltmaya yönelik bir davranışın uygulandığı her durumda, ampirik literatür uygun, uyumsuz veya alternatif olumlu bir davranışın arzu edilmeyen davranışın yerini almasını pekiştiren eşzamanlı bir prosedürün uygulanmasını desteklemektedir (Ryan ve diğerleri., 2007). Daha önce de belirtildiği gibi, bu ikili yaklaşım oto kontrol becerileri gelişen küçük yaştaki çocuk için yardımcı olmaktadır. Walker, Ramsey ve Gresham (2003) nasıl davranılacağı konusunda talimat olmadan, çocuk davranış sorunlarının süreceğini ayrıca ileri sürmektedir. Bu özellikle de bir söndürme prosedürü kullanılırken geçerlidir. Örneğin, sızlanma örneğinde, okul öncesi eğitim sınıfında sızlanmaya aldırmamak çocuk sızlanırken çocukla konuşmamak, çocuğa bakmamak veya etkileşime girmemek anlamına gelmektedir. Daha sonra, sızlanmanın önceden belirlenmiş bir süre (Ör., 3-5 saniye) için durmasına bağlı olarak, öğretmen çocuğa bakarak, konuşarak ve överek (Ör, "O sessizliği seviyorum") veya çocuk uygun ses tonu kullandığında ilgilenilerek (ör, "Sen kelime kullanıyorsun, sana nasıl yardımcı olabilirim?") alternatif sessiz ve sızlanma içermeyen davranışa dönük ilgi göstermektedir.

\section{Şarta Bağlılık}

Övgünün kullanımında olduğu gibi, şarta bağl1l1k, ivedilik ve tutarlılık planlı aldırmazlığın kullanımındaki temel unsurlardır. Spesifik olarak, uygun olmayan bir davranışa aldırmamak çocuk ilk hedef davranışı sergilemeye başladığında öğretmenin hedef davranışa aldırmaması anlamına gelmektedir. Daha sonra, davranışın sona ermesine bağlı olarak, öğretmen aldırılmayan davranışın yerini alan uygun bir davranış için çocuğu övmektedir. Örneğin, Katie "Bana sor! Bana sor!" dediğinde, öğretmen 
Katie'ye arkasını dönmektedir ve elini kaldırmış ve daha sessiz bir şekilde oturan başka bir çocuğu çağırmaktadır. Daha sonra, öğretmen başka bir soru sorduğunda, öğretmen Katie'nin fark edilmek için seslenmeden elini kaldırdığını fark etmektedir ve derhal onu çağırıp beklediği için övmektedir.

\section{İvedilik}

Olumsuz hedef davranış ile öğretmenin aldırmaması arasındaki bağlantının öğrenci için anlaşılır olmasını sağlamak için planlı aldırmazlık öğretmenin aldırmamayı planladığı davranışın meydana gelmesinden hemen sonrasında gerçekleştirilmelidir. Dolayısıyla, öğretmenin uygun olmayan bir davranışa karşı aldırmama eylemini sergilemesinin hızlı olması ve yerine gelen arzu edilen davranışı övme konusunda da hızlı olması genel bir kuraldir.

\section{Tutarlılık}

Öğretmenler çoğu zaman aslında planlı aldırmazlığı yanlış uyguladıkları için aldırmazlığın işe yaramadığından şikâyet etmektedir. Öğretmenler tutarlı olduklarına inanabilirler ancak zaman zaman farkında olmadan hedef davranışa karşı ilgi gösterebilmektedirler. Bir anlık bakış yada yüz ifadesi şeklinde ara ara gerçekleşen bu ilgilenme durumu öğretmenin ortadan kaldırmayı amaçladığı bu davranışı pekiştirebilir. Maalesef, ara ara gerçekleşen bu fireler ara ara çocuğun davranışına yönelik pekiştireçlere dönüşmektedir ve ara ara pekiştirilen bu davranış azaltılması en zor olandır (Witt, VanDerHeyden, \&Gilbertson, 2006). Dahas1, eğer öğretmenler ara sıra uygun olmayan davranışa karşı ilgi gösterirse, öğretmenin ilgisi olumsuz olsa dahi (Ör, konuşmayı kes, JJ") çocukların o davranışı yapmaya devam etmesi olasıdır. Tutarlılık ve ivedilik, planlı aldırmazlık prosedürlerinin uygulanmasında kritik öneme sahiptir (Sugai\&Horner, 2006). Planlı aldırmazlığı kullanmayı tercih eden öğretmenler, aldırmazlık eylemini dikkatli ve tutarlı bir şekilde uygulamadıkları takdirde, hedef davranışın öngörülmedik şekilde güçlenebileceğinin farkında olmalıdır.

\section{Belirlilik}

Öğretmenlerin belli ve şarta bağlı övgü kullandıkları zaman, öğrencinin davranışlarında ve akademik becerilerinde gelişme olduğunu bilmekteyiz (Sutherland, Wehby, \&Copeland, 2000). Bu, özellikle de öğretmenlerin aldırılmayan davranışın yerine çocukları uygun davranışlar için pekiştirirken 
geçerlidir. Yinelemek gerekirse, arzu edilen ve arzu edilmeyen davranışları belirgin olarak tarif etme çocuğun kabul edilmez davranış ile kendisinden beklenen davranış arasında ayrım yapmasına yardımcı olmaktadır. Örneğin, ögretmenlerin çocuklara neyi övdüklerini ve hangi uygun olmayan davranış ile ilgilenmeyeceklerini açıkça söylemeleri gerekmektedir (ör., "Jerome, bugün sınıfta konuşursan, seninle ilgilenmem yada seni kaldırmam. Elini kaldırıp sessizce oturduğunda, seni kaldırırım.”). Arzu edilen ve arzu edilmeyen davranışı belirgin olarak tarif etme, çocuğun kabul edilemez olan davranışıyla kendisinden beklenen davranışı ayırt etmesine yardımcı olmaktadir.

\section{Sonucun Özellikleri}

Bir söndürme prosedüründe, pekiştirmenin geri tutulması ile çocuktaki uygun olmayan davranışın zayıflayacağı yada sona ereceği yönünde bir varsayım vardır. Ancak, çocuğun uygun olmayan davranışlarının başka yollarla pekiştirildiği durumlar söz konusudur- çocuğun sınıf arkadaşları, çocuğun davranışın kendisinden aldığ 1 zevk yada istenmeyen bir görev veya aktiviteden kaçma imkanı (Brunhill, 2005; Gable ve diğerleri., 2009). Dolayısıyla, öğretmenler dikkatli olmalı ve çocuğun davranışının işlevini tespit etmeye çalışmalıdır (Crawford,Brockel, Schauss, \&Mittenberger, 1992). Yani, çocuğun davranışının amacı nedir? Davranış sosyal ilgi edinmeyi amaçlamakta mıdır? Davranış öz pekiştirici midir? Davranış çocuğun arzu edilmeyen bir davranıştan kaçmasını ya da kaçınmasını sağlamakta mıdır? Çocuk bu davranış aracılığıyla arzu edilen bir amaca erişebilmekte midir? Eğer öğretmen, uygun olmayan davranışa tutarl, ivedi ve şartlı bir şekilde aldırmazsa ve benzer şekilde yerine gelen tüm alternatif ve uygun davranışları överse ve uygun olmayan davranış devam ederse, öğretmenin ilgisinin uygulamadaki pekiştirici olmaması olasıdır. $\mathrm{Bu}$ durumlarda, aldırmamaya devam edebilir ancak çocuğun davranışı azalmayacaktır.

\section{Davranıșın Etkisi}

Söndürme, davranış1 sürdüren pekiştirecin aniden geri çekilmesi veya sonlandırılması ile davranışı azaltan bir prosedürdür (Zimmerman\&Zimmerman, 1962). Ancak, planlı aldırmazlığın öğretmen ilgisi nedeniyle sürdürülen bir davranışı azaltmaya veya yok etmeye yönelik bir strateji olarak kullanılacağı durumlarda söndürmeye ait anlaşılması gereken birkaç yan etki mevcuttur. Bir söndürme stratejisinde, öğretmen pekiştireci geri çekerek sistematik olarak uygun olmayan davranışa aldırmadığı zaman (yine, uygun olmayan davranışı pekiştirenlerin öğretmen 
övgüsü ve ilgisi olduğunu varsayarak), davranışsal teoriye dayanarak, uygun olmayan davranış zayıflamadan önce çoğu zaman artmaktadır (O'Leary, BeckerEvans, \&Saudargas, 1969). Uygun olmayan davranışta bu tür artış beklenmektedir. Çocuk şimdi öğretmenin ilgisini çekebilmek için öncesinden daha fazla çaba göstermektedir. Ĕger öğretmen ivedi ve tutarlı bir şekilde çocuğun davranışına aldırmamaya devam ederse, uygun olmayan davranış nihai olarak azalacaktır. Ancak, birçok öğretmen çocuğun davranışı arttığında aldırmazlığa devam etmenin zor olduğunu bulmuştur. Çocuğun davranışındaki artışın, bu davranış arkasındaki motivasyonun öğretmen ilgisi olduğunu bilmek güven vericidir. Öte yandan, eğer bir öğretmen sorumlu davranıştaki artışı geçici olarak da tolere edemezse, planlı aldırmazlık uygun bir strateji değildir. Eğer öğretmen çocuğun davranışındaki olası artıştan rahatsızlık duyuyorsa, kendisinin planlı aldırmazlığın uygulamasında tutarsız olması olasıdır. Önceden ele aldığımız gibi, tutarsız aldırmazlık, davranış üzerinde aralıklı pekiştirme ile sonuçlanabilir ve davranışı müdahaleye karşı daha dirençli hale getirebilir (Witt ve diğerleri, 2006).

Öğretmenin şarta bağlılığa, ivediliğe, tutarlılığa ve spesifisiteye bağlı kalması ve öğretmen ilgisinden dolayı sürdürülen davranışlarda kullanması kaydıyla, planlı aldırmazlık zorlayıcı davranışa sahip küçük okul öncesi eğitim çocuklarında etkili bir stratejidir. Planlı aldırmazlık ile beraber öğretmenin yerine gelecek olan uygun davranışları övmesi de aynı derecede öneme sahiptir.

\section{Sınıf İçi Kurallar}

Y1llar geçtikçe sınıf içi kurallar öğrenci güvenliği, sınıf içi düzen ve dekora yönelik standartlar belirlemiştir (Kerr\& Nelson, 2010; Van Acker, 2007). Sınıf içi kuralların az sayıda, anlaması kolay, olumlu bir şekilde belirtilmiş ve uygulanabilir olması gerektiği yönünde fikir birliği söz konusudur (Hemmeter, 2007; Gable ve diğerleri, 2009; Kerr\& Nelson, 2010). Ayrıca, akademik başarı ile ilişkili pozitif sosyal ve öz denetleyici davranışlar (Spira\&Fischel, 2005) sınıf içi kuralların sistematik uygulaması ile teşvik edilip sürdürülebilmektedir.

Birçok durumu kapsayan ve rutin sınıf içi aktiviteleri ele alan sınıf içi kurallar en sıkı olanlardır. Okul öncesi eğitim ortamlarının geneli ve aktiviteler için genelleştirilebilen basit kural örnekleri "Güvenli olun. Sorumlu olun. Saygılı olun" gibi örneklerdir. Bu tür kurallar birçok eğitimöğretim bağlamına uygundur. Eğitimcilerin çoğu kuralların sınıf ortamında öngörülebilirlik sağladığına (Van Acker, 2007) ve dolayısıyla her tür davranış yönetimi planının önemli unsuru olduğuna inanmaktadır. Ayrıca, kurallar öğrencinin kendi davranışı için artan sorumluluk kabul etmesini teşvik etmek için kullanılabilir ve kullanılmalıdır. Her formal beklenti takımı 
(sınıf ve okul geneli kurallar) çocuklara dikkatlice öğretilmelidir ve daha sonra herkesçe görülebilir bir yere asılmalı, gözden geçirilmeli ve düzenli olarak uygulanmalidır.

Bazı eğitimciler (Burden, 2006; Maag, 2004) çocukların kuralların geliştirilmesine yardımcı olmasını savunmaktadır. Çocuklar kuralların geliştirilmesi ve kuralların ihlalinin sonuçları ile ilgili düşünceleri ile yaratıcı ve bilgili olabilmektedirler. Çocuklar katılım gösterdiğinde, kurallarla içli dış1 olması daha olasıdır ancak öğretmenin olası kuralların ve ihlal sonuçlarının tartışılması esnasında öğrencilere rehberlik yapması gerekmektedir zira çocuklar çok ağır ve uygulanamaz sonuçlar önerme eğiliminde olmaktadır (Gable ve diğerleri, 2009).

Öğretmenler çoğu zaman kuralların geliştirilmesini, tartışılmasını ve duvara asılmasını onları etkin bir şekilde uygulamak ile karıştırmaktadır. Ayrıca, küçük yaştaki çocukların günden güne her bir kuralın ne anlama geleceğini bileceğini ve hatırlayacağını varsaymak bir hatadır. Çocuklara her bir sınıf içi kurala nasıl uyacakları sistematik olarak öğretilmelidir. Uygun ve kurallara uyan davranışlar model olarak gösterilmelidir ve hatalı davranışların sonuçları çocukların her bir kuralı açıkça anladığı belli olana kadar açıkça gösterilmelidir. (ör.,Burden, 2006; Kerr\& Nelson, 2006). Paine ve arkadaşları (Paine, Radicchi, Rosellini, Deutchman, \&Darch, 1983) 3-5 dakikadan daha fazla zaman almayacak şekilde kuralların günlük olarak gözden geçirilmesi gerektiğini önermektedir. Grafik düzenleyiciler (Graphicorganizers) ve öğrencilere etkileşimle destek verme stratejileri (scaffoldingstrategies) beklenen davranışları açıklığa kavuşturmada ve sınıf içi rutinlerin belirlenmesinde yardımcı olabilmektedirler (Bear, 2005; Rock, 2004). Kurallar günlük olarak gözden geçirildiğinde, çocukların zihinlerinde taze kalmaktadır ve öğretmenler bu kuralları daha tutarlı bir şekilde uygulayabilmektedir.

Artan uyumun sorunlu davranışta bir azalmaya yol açtığ 1 yönünde kanitlar mevcut olsa da (Parrish, 1986), kuralların belirlenmesi olumlu sonuçları garanti etmemektedir. Övgü ile planlı aldırmazlıkta olduğu gibi şarta bağl1lık, ivedilik, tutarlılık, belirlilik, sonuçların özelliği ve davranış üzerindeki etki kurallara uyma ve güvenli ve üretken bir öğrenme ortamına katkı sağlayan etkenlerdir.

\section{Şarta Bağlılık, İvedilik ve Tutarlıık}

Bir çocuk sınıf içi bir kurala uyduğunda, öğretmen o çocuğu sınıf içi kurala bağlı kaldığı için pekiştirmelidir. Basit bir övgü ifadesi olabilir (Ör., "Susan, düzgün oturuyorsun. Öğrenmeye hazır olduğu görebiliyorum."). Benzer şekilde, bir kural ihlalinin meydana gelmesi halinde, öğretmen o kuralı ihlal etmenin sonucunu yerine getirmelidir (Kerr\& Nelson, 2010). 
Küçük bir ihlali görmezden gelmek ve kurala uyum sağlayan bir öğrenciyi övmek uygun olabilir ve daha sonra çocuğun uygun davranışı sergilemesine bağl1 olarak, çocuk kurala uyduğu için pekiştirilmelidir. İhlal etmenin olumsuz sonucu çocuğun bilgisayarda fazla zaman geçirmesi için verilmiş olan fişi geri almak olabilir. Önemli olan kurallara uyumun ve onları ihlal etmenin önceden belirlenmiş sonuçları olması ve bunların çocuğun tanımlanan davranışları sergilemesine bağlı olarak gerçekleşmesidir. Bir şarta bağlı olmanın yanında, sonuçların davranışın meydana gelmesinden hemen sonra yerine getirilmesi gerekmektedir. Kuralların kullanımının iki boyutu vardır ve bunlar öğretmenin uygun davranışın meydana gelmesinden hemen sonra olumlu sonucu gerçekleştirme konusunda dikkatli olması ve kural ihlalinin planlanmış sonucunun uygulamasında hızlı davranılmasıdır.

Her tür sınıf düzeyindeki müdahalede olduğu gibi, öğretmenlerin her ihlalin önceden tanımlanmış sonucunun uygulanmasında tutarlı olması gerekmektedir. Bunu yerine getirmemek, kuralları etkisiz k1lmaktadır (Madsen ve diğerleri, 1968). Sınıf için kurallarının tutarsız bir şekilde uygulanması öğretmen-öğrenci çatışmasının önemli bir kaynağını oluşturmaktadır (Gable ve diğerleri., 2009). Bu, öğretmenlerin öğrencilerin kurallara uyma davranışını gözlemlemesi, uygun bir şekilde kurallara uymanın pekiştirilmesi ve ihlallerin gerçekleştikçe ele alınması (tekrarlı) gerektiğini ortaya koymaktadır (Grossman, 2004).

\section{Belirlilik}

Rhode, Jensen, ve Reavis (1992) öğrencilerin kurallara uyumunu artırmak için kesin isteklerin kullanımını önermektedir. Kesin istekler öğrencinin adı, istenilen davranışın kesin tarifi, nazik ve duygusal olmayan ses tonunun kullanımı ve öğrencinin uyması için beş saniyelik bekleme süresinden oluşmaktadır (Rhode ve diğerleri). Çocukların ne için övüldüklerini ve/veya neyi daha uygun bir şekilde yapmaları gerektiğini bilmeleri gerekmektedir. Örneğin, belirli bir kurala uymayı övmek için bir öğretmen "Olivia, Michael konuşurken onu dinleme şeklini sevdim. Başkalarına saygılı davrandın" diyebilir. Benzer şekilde, eğer Olivia konuşursa, öğretmen" Olivia, Michael konuşurken onu dinleyerek saygılı olmayı unutma" şeklinde bir hatırlatma yapabilir. Bu kurala uyum için uygun stratejiyi sağlamaktadır. Olivia sessiz kaldığında, mecbur kalmış olsa da övülmelidir.

\section{Sonucun Özellikleri}

Kural ihlali meydana geldiğinde, öğretmen ilk olarak "Güvenli olmayı unutma" şeklinde kuralın hatırlatmasını yapabilir. Eğer öğrenci koşmak yerine hemen yürümeye başlarsa, öğretmen bu uyumu övmelidir. 
"Koşmak yerine yürümeyi hatırladın. Bu senin güvenli olduğunu gösterir." Ancak, ikinci bir hatırlatma sonrasında, öğretmenin uygun davranışı modellemesi ve öğrencilere bu davranışı tekrarlatması ve uyumu övmesi gerekebilir (kural ihlali için bir strateji uygulamanın yanında). Kurala uymanın sonucu, uymamanın sonucundan daha güçlü olmasa da en az onun kadar güçlü olmalıdır (Lewis\&Sugai, 1996). Bir kural ihlalinin öğretmen ilgisi ile pekiştirilmesi halinde, sözlü olarak yeniden yönlendirmenin veya tekrar ettirmenin etkili olmayacağını ve bunun yerine öğretmenin ortadan kaldırmaya çalıştığı davranışı artıracağını hatırlayınız. Bu aşağıdaki bölümde daha ayrıntılı olarak ele alınacaktır.

\section{Davranışın Etkisi}

Öğrencilerin, öğretmenlerin kurallara uyan ile uymayan davranışların bilincinde olduğuna inandıkları zaman sınıf içi kurallara uymaları daha olasıdır (Kounin, 1970). Araştırmacılar, öğretmenlerin iki amaçlı bir strateji ortaya koymaları gerektiğini ileri sürtmektedir: (a) davranışın ileride tekrar meydana gelme olasılığını azaltmak ve (b) kabul edilebilir davranışın meydana gelme olasılığını artırmak (www.pbis.org, 2005). Okul personelinin 'adil-ikili' (fair-pair) kuralına uyması gereklıdır (White \&Haring, 1980) ve sorunlu davranışı azaltmaya yönelik bir stratejiyi ortaya koyarken uygun yedek davranışı öğretmeye yönelik başka bir stratejiyi ortaya koymaları gerekmektedir. Örneğin, kurallara uymak için övgünün (Ör, "Devon ve Shanieka, her ikiniz de o kuleyi yapmak için çok çalıştınız. Saygılı olduğunuz için bir beşlik çakınız."), öğretmenin uygun olmayan davranış1 görüp de yorum yapmasından (ör., "Devon ve Shanieka, birbirinizden blokları kapmayı kesiniz.") daha etkili olması olasıdır.

Çocuğun davranışı üzerindeki etki, müdahale stratejisinin etkili olup olmadığını belirlemektedir. Çocuğun kurala uymamasının nedeni bir işlev (a) beceri eksikliği (çocuğun o beceriye sahip olmaması), (b) performans eksikliği (çocuk o beceriye sahiptir ancak yerine getirmemektedir) yada (c) oto kontrol performans eksikliği (çocuk beceriye sahiptir ancak karş1 güçlerin üstesinden gelememektedir- öfke, gerilim, yorgunluk) olabilir (ör.,Gresham, Van, \&Cook, 2006; Van Acker, 2007). Eğer kurallara uyma artmiyorsa, öğretmenin "Kurallara uyumu artırabilmek için ne yapabilirim?" sorusunu sorması zorunludur. Dikkate alınması gereken birkaç soru vardır: Çocuk neden kurallara uymuyor? Çocuk kuralın ne anlama geldiğini anlıyor mu ve kurala nasıl uyacağını biliyor mu? Çocuk kuralı bilip uymayı reddediyor mu? Çocuğun davranışı üzerinde oto kontrol uygulamasını öğretecek bir müdahale tasarlamam gerekiyor mu? Öğretmen olarak, kurallara uyma ve uymama konusunda tutarlı oluyor muyum? Kurallara 
uyum için uygun bir pekiştirecim var mı? Kurallara uymamayı sürdüren başka etkenler var mı (Ör., sınıftaki çocukların o çocuğun kural ihlallerine gülmesi)? Her zaman öğrencinin uygun davranışının motivasyonunu tanımlama gerekli olmazken (Grossman, 2004; Lane, Gresham, \&O'Shaughnessy, 2002 karşılaştırınız), bunu kuralı üç yada daha fazla ihlal eden öğrenci için yapmak önemlidir (Gable ve diğerleri, 2009).

\section{Sonuç Tespitleri}

Küçük yaştaki çocuklara yönelik programlar, son kırk yılda önemli ölçüde değişmiştir. Günümüzde tipik okul öncesi eğitim ve ilköğretim sınıfları giderek artan heterojenliğe sahip çocuk gruplarına hizmet etmektedir. Son zamanlardaki yasal zorunluluklar beraberinde, okul çağındaki nüfusun kültürel ve dilsel çeşitliliğindeki hızlı büyüme, (IDEA, 1997, 2004; NCLB, 2001) sinıf öğretmenlerinden beklenenler ve sorumlulukları üzerinde dramatik bir etkiye sahiptir (Bagby, Rudd, $\&$ Woods, 2005). Günümüzde herhangi bir sınıfa kaydolan çocukların onlarca yıl önce görülmeyen bir dizi yeteneği ve zorlukları mevcuttur. Sinıftaki artan davranışsal zorluklar beraberinde, bu gerçeklikler öğretmenler arasında daha yüksek ilgi oranına ve çocuklar için olumsuz uzun vadeli sonuçlara katkı sağlamaktadır. Çocukların davranışsal bozukluklarını çözmeye yönelik tek bir çözüm mevcut olmasa da, öğretmenlerin küçük yaştaki çocukların sosyal duyusal gelişiminde ve eğitimsel başarısında önemli rol oynadıklarını biliyoruz. Kanıta dayalı uygulamalara (NCLB) yapılan vurgu 1şı̆̆ında, ampirik destek bakımından zamana dayanan üç adet temel, kullanıma hazır bulunan stratejiyi inceledik. Ele aldığımız stratejilerden her biri okul geneli olumlu davranışsal desteklerin bütünleşik bir parçası olabilecek sınıf düzeyinde müdahaleyi yansıtmaktadır (Scheuermann\&Hall, 2008). Bu stratejilerin çocuk davranış1 ve beceri edinimi üzerinde olumlu etki yaratabileceği, öğrenci ile öğretmen arasındaki ilişkinin gelişmesine katkı sağladığı ve paralel olarak öğretmenin öz yeterlilik hissi üzerinde etki ettiğine dair çok güçlü kanıtlar mevcuttur. Doğru ve sağduyulu bir şekilde kullanıldığında, övgü, planlı aldırmazlık ve sınıf içi kurallar çeşitli geçmişlere, becerilere ve ihtiyaçlara sahip çocukların başarılı öğrenciler olabileceği güvenli ve öngörülebilir bir öğrenme topluluğunun temelini oluşturabilir.

Sınıf içerisinde etkin bir şekilde uygulandığında, övgü, planlı aldırmazlık ve sınıf içi kuralların etkinliğine karşın, daha fazla inceleme gerektiren birkaç değişken bulunmaktadır. Örneğin, araştırmacıların bu stratejilerin olumlu öğretmen-çocuk etkileşimini artıran ve destekleyen kesin özelliklerini tarif etmesi ve doğrulaması gerekmektedir. Dahası, araştırmacıların öğretmenlerin bu stratejileri daha etkin kullanması için 
ihtiyaç duydukları destek türlerini tanımlamaları gerekmektedir. Ayrıca, geleceğin öğretmenlerine sadece teorik temelleri sağlayarak değil de ayrıca sınıf içerisinde başarılı bir uygulama için gereken becerileri sağlayarak öğretmen eğitim programlarında bu destek stratejilerini dahil edecek profesyonel gelişim programlarına ihtiyaç vardır. Çocuğun öğrenmesi ve davranış1, öğretmen-çocuk etkileşimi dâhilindedir ve ancak hem çocuğun eğitimini ve olumlu davranışını geliştirecek desteklere hem de öğretmenlerin kanıta dayalı stratejilerin etkin uygulamasını öğrenmeleri, uygulamaları ve sürdürmeleri için gereken desteklere odaklandığımızda, savunmuş olduğumuz kaliteli öğretmen etkileşimlerini günlük olarak görmeye başlayacağız.

\section{KAYNAKLAR}

Alberto, P., \& Troutman, A. (2009). Applied behavior analysis for teachers (8th ed.). Upper Saddle River, N.J.: Merrill.

Anderson, L. F., \& Hendrickson, J. M. (2007). Early-career EBD teacher knowledge, ratings of competency importance, and observed use of instruction and management competencies. Education and Treatment of Children, 30(4), 43-65.

Bear, G. (2005). Developing self-discipline and preventing and correcting misbehavior. Boston. Pearson Allyn and Bacon.

Becker, W. C., Madsen, C. H., Arnold, C. R., \& Thomas, D. R. (1967). The contingent use of teacher attention and praise in reducing classroom behavior problems. Journal of Special Education, 1, 287-307.

Bagby, J. H., Rudd, L. D., \& Woods, M. (2005). The effects of socioeconomic diversity on the language, cognitive and socialemotional development of children from low-income backgrounds. Early Child Development and Care, 175(5), 395-405.

Boggiano, A. K., Main, D. S., \& Katz, P. A. (1988). Children's preference for challenge: The role of perceived competence and control. Journal of Personality and Social Psychology, 54, 134-141.

Brophy, J. (1981). Teacher praise: A functional analysis. Review of Educational Research, 51, 5-32.

Brophy, J. (1988). Educating teachers about managing classrooms and students. Teaching and Teacher Education, 4(1), 1-18.

Brophy, J. (1998). Motivating students to learn. Boston: McGraw Hill.

Burden, P. (2006). Classroom management: Creating a successful K-12 learning community. (3rd ed.). Hoboken, NJ: Wiley.

Conroy, M. A., Hendrickson, J. M., \& Hester, P. P. (2004). Early identification and prevention of emotional and behavioral disorders. In R. B. Rutherford, M. M. Quinn, \& S. Mathur (Eds.), Handbook of research in behavioral disorders (pp. 199-215). NY: Guilford Publications. 
Crawford, J., Brockel, B., Schauss, S., \& Mi $\square$ enberger, R. M. (1992). A comparison of methods for the functional assessment of stereotypic behavior. Journal of the Association for Persons with Severe Handicaps, 17, 77-86.

De Kruif, R.E.L., McWilliam, R. A., Ridley, S. M., \& Wakely, M. B. (2000). Classification of teachers' interaction behaviors in early childhood classrooms. Early Childhood Research Quarterly, 15(2), 247-268.

Dodge, K. A. (1993). The future of research on the treatment of conduct disorder. Development and Psychopathology, 5, 311-319.

Feldman, S. (2003). The place for praise. Teaching PreK-8, 5, 6.

Filcheck, H., McNeil, C., \& Herschell, A. (2001). Types of verbal feedback that affect compliance and general behavior in disruptive and typical children. Child Study Journal, 31, 225-248.

Gable, R. A., Hester, P. P., Rock, M., \& Hughes, K. (2009). Back to basics-Rules, praise, ignoring, and reprimands revisited. Intervention in School and Clinic, 44(4), 195-205.

Gresham, F., M., Van, M. B., \& Cook, C. R. (2006). Social skills training for teaching replacement behaviors: Remediating acquisition deficits in at risk students. Behavioral Disorders, 32, 363-377.

Grossman, H. (2004). Classroom behavior management for diverse and inclusive schools. (3rd ed.). New York: Rowman \& Li $\square$ lefield Publishers, Inc.

Hattie, J., \& Timperley, H. (2007). The power of feedback. Review of Education Research, 77(1), 81-112.

Hemmeter, M. L. (October, 2007). Program wide approaches to behavior support in early childhood se $\square$ ings. CCBD International Conference on Behavior Disorders. Dallas, TX. Individuals with Disabilities Education Act of 1997, P.L. 105-17. Individuals with Disabilities Education Improvement Act of 2004, P.L. 108-446.

Kaiser, A. P., \& Hester, P. P. (1997). Prevention of conduct disorders through early intervention: A social-communicative perspective. Behavioral Disorders, 22(3) 117-130.

Kast, A., \& Connor, K. (1988). Sex and age differences in response to informational and controlling feedback. Personality and Social Psychology Bulletin, 14(3), 514-523.

Kauffman, J. M., \& Landrum, T. L. (2008). Characteristics of emotional and behavioral disorders of children and youth. Upper Saddle River: Prentice Hall.

Kendziora, K. T. (2004). Early intervention for emotional and behavioral disorders. In R. B. Rutherford, M. M. Quinn, \& S. Mathur (Eds.), Handbook of research in emotional and behavioral disorders (pp. 327-351). NY: Guilford Publications.

Kern, L., White, G. P., \& Gresham, F. M. (2007). Educating students with behavioral challenges. Principal, 86(4), 56-59.

Kerr, M. M., \& Nelson, C. M. (2010). Strategies for addressing behavior problems in the classroom. (6th Ed.). Columbus OH: Merrill.

Lane, K. L., Gresham, F. M., \& O'Shaughnessy, T. E. (2001). Interventions for children with or at risk for emotional and behavioral disorders. Boston: Allyn \& Bacon. 
Lewis, T., \& Sugai, G. (1996). Descriptive and experimental analysis of teacher and peer attention and the use of assessment-based intervention to improve prosocial behavior. Journal of Behavioral Education, 6, 6-24.

Loeber, R., Burke, J. D., Lahey, B. B., Winters, A., \& Zera, M. (2000). Oppositional defiant and conduct disorder: A review of the past 10 years, Part 1. Journal of the American Academy of Child \& Adolescent Psychiatry, 39, 1468-1484.

Long, N., \& Morse, W. (1996). Conflict in the classroom: The education of at-risk and troubled students. Austin, TX: Pro-ED.

Maag, J. W. (2004). Behavior management: From theoretical implications to practical applications. (2nd ed.). Belmont, CA: Wadsworth/Thompson Learning.

Madsen, C. M., Becker, W. C., \& Thomas, D. R. (1968). Rules, praise, and ignoring: Elements of elementary classroom control. Journal of Applied Behavior Analysis, 1, 139-150.

Markowitz, J., Carlson, E., Frey, W., Riley, J., Shimshak, A., Heinzen, H., et al. (2006). Preschoolers' characteristics, services, and results:Wave 1 overview report from the pre-elementary education longitudinal study (PEELS). Rockville, MD: Westat.

McCarty, T., Griffin, S., Appolloni, T., \& Shores, R. (1977). Increased peerteaching with group-oriented contingencies for arithmetic performance in behavior-disordered adolescents. Journal of Applied Behavior Analysis, 10, 313.

McEvoy, A., \& Welker, R. (2000). Antisocial behavior, academic failure, and school climate: A critical review. Journal of Emotional and Behavioral Disorders, 8(3), 130-140.

National Center of Education Statistics. (2002). Schools and staffing survey, 19992000: Overview of the data for public, private, public charter, and Bureau of Indian Affairs elementary and secondary schools.

No Child Left Behind Act of 2001, P.L. 107-110.

O’Leary, K. A., Becker, W. C., Evans, M. B., \& Saudargas, R. A. (1969). A token reinforcement program in a public school. A replication and systematic analysis. Journal of Applied Behavior Analysis, 2, 3-13.

Ollendick, T. H., \& Shapiro, E. S. (1984). An examination of vicarious reinforcement processes in children. Journal of Experimental Child Psychology, 37, 78-91.

Paine, S. C., Radicchi, J., Rosellini, L. C., Deutchman, L., \& Darch, C. B. (1983). Structuring your classroom for academic success. Champaign, IL: Research Press.

Parrish, J. (1986). Experimental analysis of response covariation among compliant and inappropriate behaviors. Journal of Applied Behavior Analysis, 19, 241254.

Pianta, R. (2006). Classroom management and relationships between children and teachers: Implications for research and practice.

In C. Evertson \& C. Weinstein (Eds.), Handbook of Classroom Management: Research, Practice, \& Contemporary Issues (pp. 685-710). Mahwah, NJ: Lawrence Erlbaum Associates. 
Pianta, R. C., La Paro, K. M., Payne, C., Cox, M. J., \& Bradley, R. (2002). The relation of kindergarten classroom environment to teacher, family, and school characteristics and child outcomes. The Elementary School Journal, 102(3), 225-238.

Raver, C., \& Knitzer, J. (2002). Ready to enter: What research tells policymakers about strategies to promote social and emotional school readiness among three- and four-year old children. New York, NY: National Center for Children in Poverty.

Rhode, G., Jensen, W. R., \& Reavis, K. (1992). The tough kid book: Practical classroom management strategies. Longmont, CO: Sopris West.

Rock, M. (2004). Graphic organizers: Tools to build behavioral literacy and foster emotional competency. Intervention in School and Clinic, 40, 10-37.

Ryan, J. B., Sanders, S., Katsiyannis, \& Yell, M. I. (2007). Using timeout effectively in the classroom. Teaching Exceptional Children, 39(4), 60-67.

Scheuermann, B. K., \& Hall, J. A. (2008). Positive behavioral supports for the classroom. Upper Saddle River: Merrill.

Shores, R. E., Gunter, P. L., \& Jack, S. L. (1993). Classroom management strategies: Are they se $\square$ ing events for coercion? Behavioral Disorders, 18, 92102.

Spiker, D., Hebbeler, K., \& Mallik, S. (2005) Developing and implementing early intervention programs for children with established disabilities. In M. J. Guralnick (Ed.), The developmental systems approach to early intervention (pp. 305-350). Baltimore:Brookes.

Spira, E. G., \& Fischel, J. E. (2005). The impact of preschool inattention, hyperactivity, and impulsivity on social and academic development: A review. Journal of Child Psychology and Psychiatry, 46(7), 755-773.

Stormont, M., Smith, S. C., \& Lewis, T. J. (2007). Teacher implementation of precorrection and praise statements in Head Start classrooms as a component of a program-wide system of positive behavioral support. Journal of Behavioral Education, 16, 280-290.

Strain, P. S., \& Timm, M. A. (2001). Remediation and prevention of aggression: An evaluation of the RIP program over a quarter century. Behavioral Disorders, 26(4), 297-313.

Strain, P. S., \& Joseph, G. E. (2004). A not so good job with "good job": A response to Kohn 2001. Journal of Positive Behavioral Interventions, 6 (1), 55-60.

Sugai, G., \& Horner, R. H. (2006). A promising approach for expanding and sustaining school-wide positive behavior support. School Psychology Review, 35, 2, 245-259.

Sutherland, K., \& Wehby, J. (2001). The effect of self-evaluation of teaching behavior in classrooms for students with emotional and behavioral disorders. The Journal of Special Education, 35(3), 161-171.

Sutherland, K., Wehby, J., \& Yoder, P. (2002). Examination of the relationship between teacher praise and opportunities for students with EBD to respond to academic requests. Journal of Emotional and Behavioral Disorders, 10(1), 5 14. 
Van Acker, R. (February, 2007). Strategies for dealing with classroom aggression. Paper presented at the Working Forum of the Council for Children with Behavioral Disorders. Las Vegas, NV.

Walker, H. M., Colvin, G., \& Ramsey, E. (1999). Antisocial behavior in schools: Strategies and best practices. (2nd ed.). Pacific Grove:Brookes/Cole.

Walker, H. M., Ramsey, E., \& Gresham, F. M. (2004). Antisocial behavior at school: Evidence-based practices. Belmont, CA: Wadsworth/Thompson Learning.

Webster-Stratton, C. (1997). Early intervention for families of preschool children with conduct problems. In M. Guralnick (Ed.), The effectiveness of early interventions (pp. 429-453). Baltimore, MD:Paul H. Brookes.

Webster-Stra $\square$ on, C. (2000). Oppositional-defiant and conduct-disordered children. In M. Hersen \& R. T. Ammerman (Eds.), Advanced abnormal child psychology (2nd ed.) (pp. 387-412). Hillsdale, NJ: Lawrence Erlbaum.

White, O. R., \& Haring, N. G. (1980). Exceptional teaching: A multimedia training package. Columbus, $\mathrm{OH}$ : Merrill.

Witt, J., VanDerHeyden, A., \& Gilbertson, D. (2006). Troubleshooting behavioral interventions: A systematic process for finding and eliminating problems. School Psychology Review, 33(3), 363-383.

Zimmerman, E. H., \& Zimmerman, J. (1962). The alteration of behavior in an elementary classroom. Journal of the Experimental Analysis of Behavior, 5, $50-60$. 